Marquette University

e-Publications@Marquette

1-1-2009

\title{
Octamethoxydibenzochrysene: Isolation and X-ray Crystallographic Characterization of a Twisted Polyaromatic Cation Radical
}

Tushar Navale

Marquette University

Linyi Zhai

Marquette University

Sergey V. Lindeman

Marquette University, sergey.lindeman@marquette.edu

Rajendra Rathore

Marquette University

Accepted version. Chemical Communications, No. 20 (2009): 2857-2859. DOI. (C) 2009 Royal Society of Chemistry. Used with permission. 


\section{Marquette University \\ e-Publications@Marquette}

\section{Chemistry Faculty Research and Publications/College of Arts and Sciences}

This paper is NOT THE PUBLISHED VERSION; but the author's final, peer-reviewed manuscript. The published version may be accessed by following the link in th citation below.

Chemical Communications, No. 20 (2009): 2857-2859. DOI. This article is (C Royal Society of Chemistry and permission has been granted for this version to appear in e-

Publications@Marquette. Royal Society of Chemistry does not grant permission for this article to be further copied/distributed or hosted elsewhere without the express permission from Royal Society of Chemistry.

\section{Octamethoxydibenzochrysene: Isolation and X-ray Crystallographic Characterization of a Twisted Polyaromatic Cation Radical}

Tushar S. Navale

Department of Chemistry, Marquette University, Milwaukee, WI

Linyi Zhai

Department of Chemistry, Marquette University, Milwaukee, WI

Sergey V. Lindeman

Department of Chemistry, Marquette University, Milwaukee, WI

Rajendra Rathore

Department of Chemistry, Marquette University, Milwaukee, WI

\section{Abstract}

The isolation and X-ray crystal structure determination of octamethoxydibenzochrysene (3) cation radical together with DFT calculations allow us to delineate evidence that the complex structural 
changes (i.e. elongation and shortening of various bonds) in a polyaromatic hydrocarbon can be predicted based on the positioning of the largest bonding and antibonding character of the HOMO.

The study of polyaromatic hydrocarbons has attracted considerable attention since these molecules hold potential to serve as building blocks for the preparation of functional electronic and optoelectronic devices. ${ }^{1}$ Of these, dibenzochrysene, a twisted polyaromatic hydrocarbon, and its derivatives have been explored by Swager and coworkers ${ }^{2}$ and others ${ }^{3}$ for the preparation of sensors, non-linear optical and liquid-crystalline materials, etc. The aromaticity and structure of parent dibenzochrysene and its dication (formed by 2-electron oxidation) has been probed both theoretically ${ }^{4}$ and experimentally, ${ }^{5}$ however, structural information is completely lacking.

Our continuing interest in the design and syntheses of stable organic cation radicals, or hole carriers, which are of fundamental importance to organic materials science,${ }^{6}$ prompted the synthesis of octamethoxydibenzochrysene (3), and isolation and X-ray crystallographic characterization of its cation-radical salt. The availability of the X-ray structural data on the first cationic dibenzochrysene allows us to provide definitive evidence as to how a hole (formed by $1 \mathrm{e}^{-}$oxidation) induces complex bond length changes in a polyaromatic hydrocarbon as well as a verification of the experimentally observed structural changes by DFT calculations. The details of these preliminary findings are described herein.

The octamethoxydibenzochrysene (3) was obtained by an oxidative cyclodehydrogenation of tetrakis(3,4-dimethoxyphenyl)ethylene (2) using $\underline{\mathrm{FeCl}_{3}}$ as an oxidant in a mixture of dichloromethane and nitromethane in $60 \%$ isolated yield. The tetraveratrylethylene (2), in turn, was prepared from McMurry coupling of the corresponding tetramethoxybenzophenone ${ }^{7}(\mathbf{1})$ in $92 \%$ yield (see Scheme 1). The structure of $\mathbf{3}$ was established by ${ }^{1} \mathrm{H} /{ }^{13} \mathrm{C}$ NMR spectroscopy and further

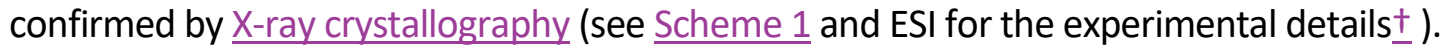

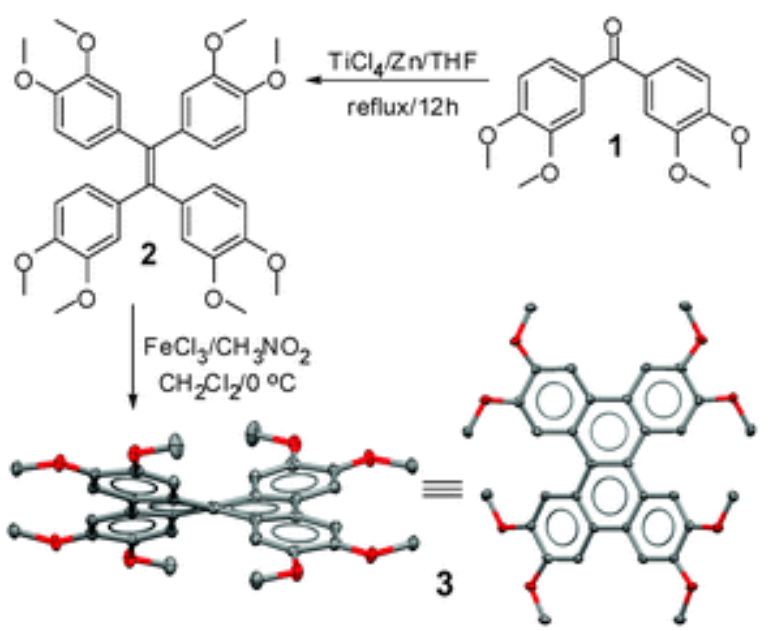

Scheme 1 Synthesis of octamethoxydibenzochrysene (3) and its ORTEP diagrams with twisted structure (thermal ellipsoids: $50 \%$ probability).

The electron donor strength of octamethoxydibenzochrysene (3) was evaluated by electrochemical oxidation at a platinum electrode as a $2 \times 10^{-3} \mathrm{M}$ solution in dichloromethane containing $0.2 \mathrm{Mn}-\underline{\mathrm{Bu}_{4} \mathrm{NPF}_{6}}$ as the supporting electrolyte. The cyclic 
voltammograms of $\mathbf{3}$, if terminated before the start of the third oxidation event, showed two reversible oxidation waves (Fig. 1A), which consistently met the reversibility criteria at various scan rates of $25-500 \mathrm{mV} \mathrm{s}^{-1}$, as they all showed cathodic/anodic peak current ratios of $i_{\mathrm{a}} / i_{\mathrm{c}}=1.0$

(theoretical) as well as the differences between anodic and cathodic peak potentials of $E_{\mathrm{pa}}-E_{\mathrm{pc}} \approx 70$ $\mathrm{mV}$ at $22^{\circ} \mathrm{C}$ (Fig. 1B). The reversible oxidation potentials of $\mathbf{3}$ were calibrated with ferrocene as internal standard ( $E_{\mathrm{ox}}=0.45 \mathrm{~V}$ vs. SCE) and were found to be 0.91 and $1.27 \mathrm{~V}$ vs. SCE corresponding to the formation of monocation and dication, respectively. It is noted that the third oxidation wave in the cyclic voltammogram of $\mathbf{3}$ displays a quasi-reversible oxidation wave $\left(E_{\mathrm{ox} 3}=1.69 \mathrm{~V}\right)$ which, in turn, distorts the other waves corresponding to the first and second oxidation events (see Fig. 1A).
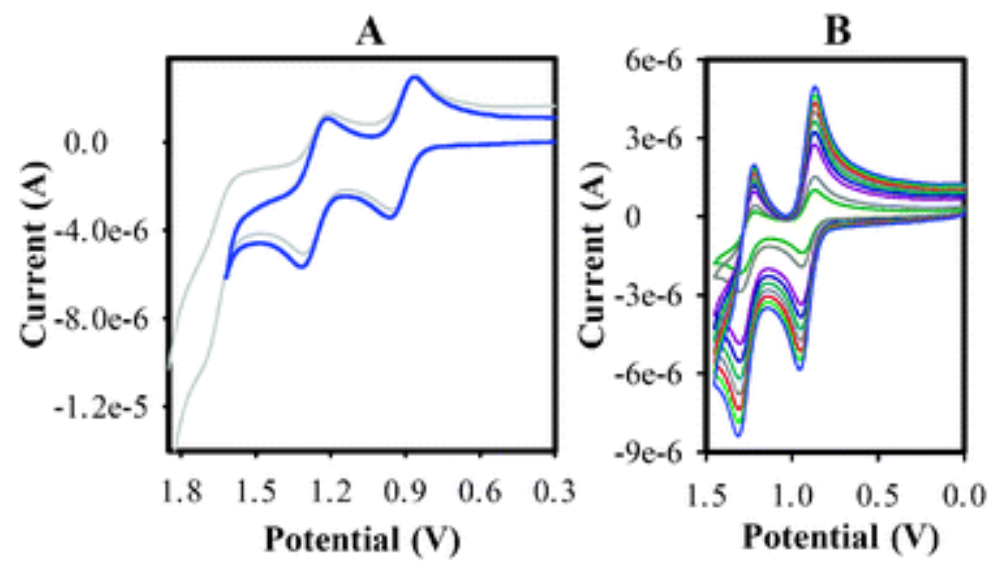

Fig. 1 (A) Cyclic voltammograms of $2 \times 10^{-3} \mathrm{M} 3$ in $\mathrm{CH}_{2} \mathrm{Cl}_{2}$ containing $0.2 \mathrm{M} n-\mathrm{Bu}_{4} \underline{\mathrm{NPF}_{6}}$ at a scan rate of $200 \mathrm{mV} \mathrm{s}^{-1}$ and (B) cyclic voltammograms of 3 at scan rates of $25-500 \mathrm{mV} \mathrm{s}^{-1}$ at $22{ }^{\circ} \mathrm{C}$.

The electrochemical reversibility of $\mathbf{3}$ and its relatively low oxidation potential permits its ready oxidation to the corresponding cation radical using either a hydroquinoneethercation radical $\left(\mathrm{CRET}^{+} \mathrm{SbCl}_{6}^{-} ; E_{\text {red }}=1.11 \mathrm{~V} \text { vs. SCE}\right)^{8}$ or magic blue $\left(\mathrm{MB}^{+} \mathrm{SbCl}_{6}^{-} ; E_{\text {red }}=1.15 \mathrm{~V} \text { vs. SCE}\right)^{\circ}$ as oxidants.

Thus, Fig. 2A shows the spectral changes attendant upon the reduction of blue $\mathrm{MB}^{+^{*}}\left(\lambda_{\max }=728\right.$ $\mathrm{nm}, \log \varepsilon_{728}=4.45$ ) by incremental additions of sub-stoichiometric amounts of 3 in dichloromethane at $22^{\circ} \mathrm{C}$. The presence of multiple isosbestic points at $\lambda=355,387,564$, and $783 \mathrm{~nm}$ (see Fig. $2 \mathrm{~A}$ ) indicates a simple electron transfer from 3 to $\mathbf{~ M B}^{\mathbf{+}^{*}}$ without decomposition of $3^{+}$. Furthermore, a plot of formation of $3^{+^{*}}$ (i.e. an increase in the absorbance at $890 \mathrm{~nm}$ against the increments of added 3 , Fig. $2 \mathrm{~B}$ ) established that $\mathbf{~ M B}^{+{ }^{+}}$was completely consumed after the addition of 1 equiv. of 3; and the resulting highly structured absorption spectrum of the $\mathbf{3}^{\mathbf{+}^{*}}$ [with intense absorption bands at $\lambda_{\max }=890\left(\log \varepsilon_{890}=4.37\right), 513,458$, and $394 \mathrm{~nm}$ and relatively weak bands at $\lambda_{\max }=636\left(\log \varepsilon_{634}=3.67\right)$ and $784 \mathrm{~nm}$ ) remained unchanged upon further addition of neutral 3, i.e., eqn (1). 
It is noted that although an identical spectrum of $\mathbf{3}^{\mathbf{+}^{-}}$was obtained when CRET $^{\mathbf{+}^{*}}$ was treated with an equimolar amount of $\mathbf{3}$, a clean spectral titration plot with isosbestic point could not be obtained owing to an overwhelming overlap of the absorption band of CRET $^{+}$at $518 \mathrm{~nm}$ with that of $\mathbf{3}^{\mathbf{+}^{*}}$ (see ESI $I_{-}$). It is further noted that the intensely colored solution of $3^{+^{*}}$, obtained according to eqn (1) or using CRET $^{+}$, was stable at ambient temperature and did not show any decomposition during a $48 \mathrm{~h}$ period at $22{ }^{\circ} \mathrm{C}$, as confirmed by UV-Vis spectroscopy. Moreover, a reduction of $\mathbf{3}^{{ }^{*}}$ with zinc dust regenerated the neutral $\mathbf{3}$ quantitatively as confirmed by ${ }^{1} \mathrm{H}$ NMR spectroscopy.
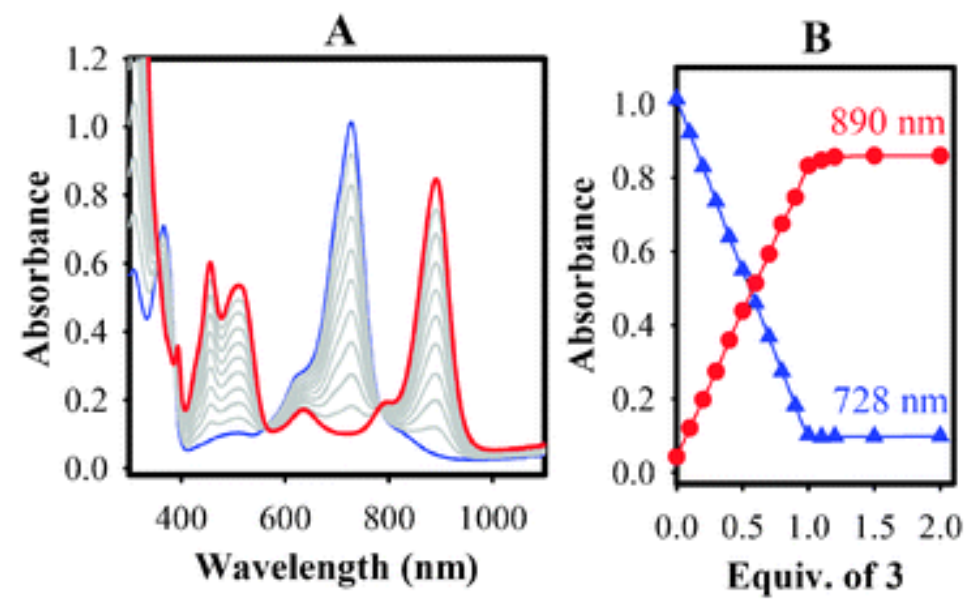

Fig. 2 (A) The spectral changes observed upon the reduction of $3.6 \times 10^{-5} \mathrm{M} \mathrm{MB}^{+}$by an incremental addition of substoichiometric amounts of 3 in $\mathrm{CH}_{2} \mathrm{Cl}_{2}$ at $22{ }^{\circ} \mathrm{C}$. (B) A plot of depletion of absorbance of $\mathbf{M B}^{+\cdot}$ (blue triangles, at $728 \mathrm{~nm}$ ) and an increase of the absorbance of $\mathbf{3}^{\circ}$ (red circles, at $890 \mathrm{~nm}$ ) against the equivalents of added neutral 3 .

The high stability of $3^{+}{ }^{-} \mathrm{SbCl}_{6}{ }^{-}$in solution prompted us to attempt the isolation of its crystalline salt as follows. For example, an excellent crop of dark-colored crystals, suitable for X-ray crystallographic studies, were obtained by a slow diffusion of toluene in a dichloromethane solution of $3^{+} \mathrm{SbCl}_{6}^{-}$, obtained using a $1: 1$ mixture of 3 and $\mathrm{CRET}^{+} \mathrm{SbCl}_{6}{ }^{-}$, during a period of $24 \mathrm{~h}$ at $\sim 0{ }^{\circ} \mathrm{C}$.

The crystal structure of $3^{*}+\mathrm{SbCl}_{6}{ }^{-}$revealed that cationic dibenzochrysene moieties form infinite stacks along the $z$ axis with non-equivalent interplanar separations of 3.31 and $3.44 \AA$. The robust $\pi-$ $\pi$ stacking arrangements amongst the molecules of the cationic 3 leads to a clathrate structure with large channels that are filled with $\mathrm{SbCl}_{6}{ }^{-}$counter anions and multiple dichloromethane molecules (see Fig. $3 \mathrm{~A} / \mathrm{B}$ ). In contrast, the packing in the crystal structure of neutral $\mathbf{3}$ is dominated not by $\pi-\pi$ but by $\mathrm{CH} \cdots \pi$ interactions amongst the methoxy groups and the electron-rich aromatic rings of the neighboring molecules. The resulting honeycomb-like layers, formed perpendicular to the crystallographic $x$-axis, are interspaced by disordered dichloromethane molecules (see Fig. 3D); and the layers are separated by copious amounts of acetonitrile molecules (see Fig. 3C). \pm 

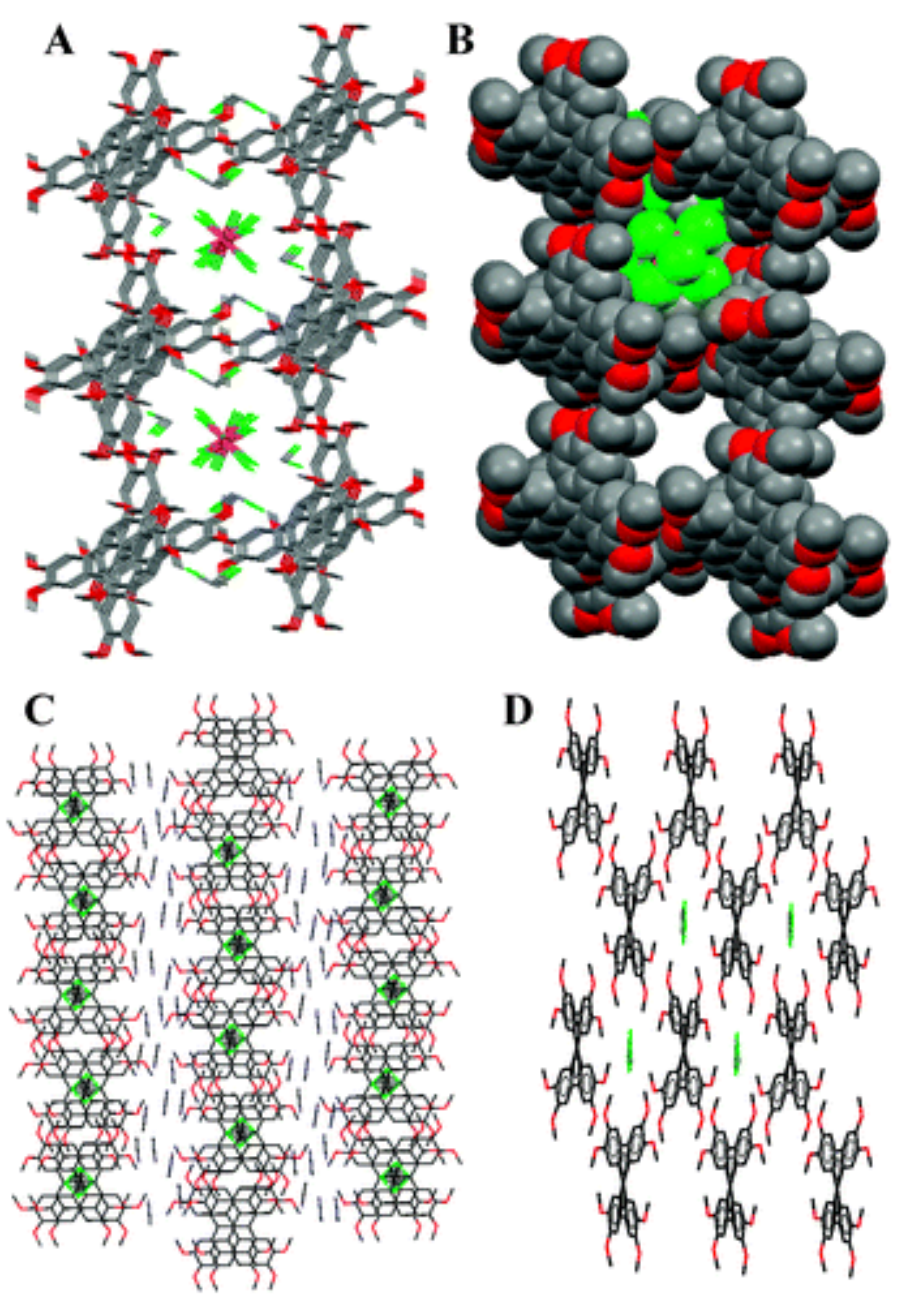

Fig. 3 (A) The packing diagram of $3^{+} \mathrm{SbCl}_{6}{ }^{-}$showing that the channels formed by stacked $3^{*+}$ are filled with $\mathrm{SbCl}_{6}{ }^{-}$and $\mathrm{CH}_{2} \mathrm{Cl}_{2}$ molecules. (B) Space filling representation of the packing diagram of $3^{-}{ }^{-} \mathrm{SbCl}_{6}{ }^{-}$where one of the channels is shown without $\mathrm{SbCl}_{6}{ }^{-}$and $\mathrm{CH}_{2} \mathrm{Cl}_{2}$ molecules. (C) The packing diagram of neutral $\mathbf{3}$ showing the layered structure where the layers are separated by acetonitrile molecules. (D) The arrangement of $\mathbf{3}$ with embedded $\mathrm{CH}_{2} \mathrm{Cl}_{2}$ molecules within a single layer of neutral 3.

An inspection of the bond length changes in the cation radical $3^{+}$, together with a comparison of its neutral form, points to the following salient features. (i) Neutral $\mathbf{3}$ has a crystallographic 2 -fold symmetry and its planarity is substantially distorted by twisting around the central $\mathrm{C}=\mathrm{C}$ bond (denoted as A, see Table 1) by $25.8^{\circ}$ and around the central bonds of "biphenyl" fragments (denoted by I) by $11.4^{\circ}$. One electron oxidation of 3 results only in a minor amplification of the distortions as judged by the slightly increased twist angles of 29.1 and $11.9^{\circ}$ for bonds $A$ and $\mathbf{I}$, respectively. (ii) As in various other aryl-methyl ether cation radicals, ${ }^{10} \mathrm{O}-\mathrm{C}\left(\right.$ ar) bonds (denoted as $\mathbf{J}$ and $\mathbf{L}$ ) in $\mathbf{3}^{\mathbf{+}^{*}}$ exhibit shortening by $\sim 1.3 \mathrm{pm}$ due to an increased $p-\pi$ dative interaction. (iii) Although the rearrangement of the lengths of various bonds (i.e. elongation and shortening) in the polyaromatic moiety in $\mathbf{3}^{\mathbf{+}^{+}}$has a complex character (see Table 1), the changes clearly correspond to the predominant contributions from the resonance structures $\mathrm{I} / \mathrm{II}$, as judged by the significant lengthening of bonds $\mathbf{A}, \mathbf{C}, \mathbf{F}, \mathbf{I}$, 
and $\mathbf{M}$ and shortening of bonds $\mathbf{B}, \mathbf{G}, \mathbf{J}$, and $\mathbf{L}$ and only a minor contribution from the resonance structures III/IV (see below).

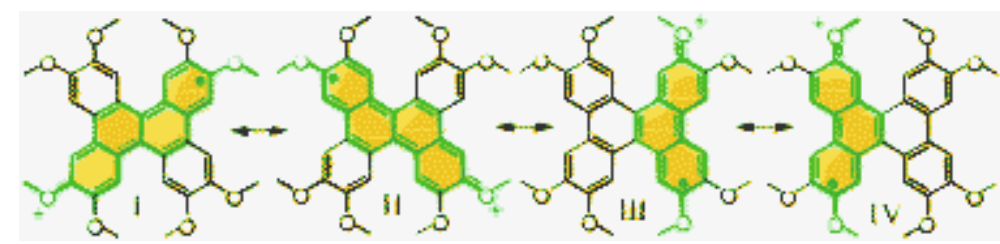

Table 1 Experimental and theoretical bond lengths of the neutral and cation radical of $\mathbf{3}$ presented in picometres (pm). Numbering scheme for the skeleton of $\mathbf{3}$ and its HOMO, obtained by DFT calculations at B3LYP/6-31G* level

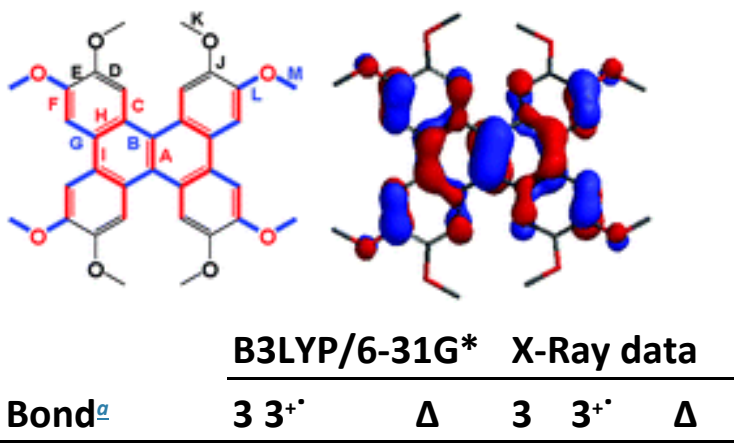

a Average of equivalent bonds.
A $140.3144 .0+3.7141 .4143 .0+1.6$
B $145.8144 .1-1.7145 .5143 .9-1.4$
C $142.2142 .4+0.2141 .5142 .3+0.8$
D $138.1138 .0-0.1136 .9136 .90 .0$
E $142.4143 .0+0.6141 .9142 .5+0.6$
F $138.1139 .3+1.2137 .8138 .2+0.4$
G $141.7140 .4-1.3142 .0140 .1-1.9$
H $141.7142 .2+0.5141 .6141 .60 .0$
I $145.2146 .3+1.1145 .3146 .5+1.2$
J $136.3135 .1-1.2137 .0135 .8-1.2$
K $141.6142 .3+0.7143 .3143 .2-0.1$
L $136.2134 .1-2.1136 .3134 .9-1.4$
M $141.6142 .7+1.1142 .9144 .2+1.3$

$\sigma-\quad-\quad-\quad 0.5 \quad 0.4 \quad-$

The experimental observations of the bond length changes in $3^{+^{*}}$ were found to be in reasonable agreement with the calculated values using DFT calculations at the B3LYP/6-31G* level (see Table 1). Furthermore, the experimentally observed elongation and shortening of the bonds in $3^{+^{*}}$ tracked 
remarkably well with the positioning of the largest bonding and antibonding character of HOMO in $\mathbf{3}$ (see Table 1).

In summary, octamethoxydibenzochrysene (3) is easily accessed from readily available starting materials and it undergoes reversible electrochemical oxidation and forms a highly robust cationradical salt. The X-ray crystal structure determination of $3^{+}{ }^{-} \mathrm{SbCl}_{6}{ }^{-}$as well as neutral $\mathbf{3}$ together with DFT calculations provides unequivocal evidence that an introduction of a cationic charge (or polaron) in polyaromatic hydrocarbon 3 leads to a complex elongation and shortening of the various bonds. The observed bond length changes in $3^{{ }^{+}}$can be readily reconciled by the positioning of the largest bonding and antibonding character of the HOMO in neutral 3. The close packing of the molecules of the cationic 3 in the crystals produces large channels akin to those found in zeolites and may allow the preparation of potentially useful conducting materials by utilizing electro-active counter anions. ${ }^{11}$

We thank the National Science Foundation (CAREER Award) for financial support.

\section{Notes and references}

1. (a) J. Wu, W. Pisula and K. Muellen, Chem. Rev., 2007, 107, 718 ; (b) A. P. H. J. Schenning and E. W. Meijer,Chem. Commun., 2005, 3245

2. (a) J.-S. Yang and T. M. Swager, J. Am. Chem. Soc., 1998, 120, 5321 ; (b) S. Yamaguchi and T. M. Swager, J. Am. Chem. Soc., 2001, 123, 12087 ; (c) A. Rose, J. D. Tovar, S. Yamaguchi, E. E. Nesterov, Z. Zhu and T. M. Swager,Philos. Trans. R. Soc. London, Ser. A, 2007, 365, 1589 , and references therein.

3. (a) S. Kumar and S. K. Varshney, Mol. Cryst. Liq. Cryst. Sci. Technol., Sect. A, 2002, 378, 59 ;

(b) C.-W. Li, C.-I. Wang, H.-Y. Liao, R. Chaudhuri and R.-S. Liu, J. Org. Chem., 2007, 72, 9203 ;

(c) V. M. Vincent and J. D. Wright,J. Chem. Soc. Perkin Trans. 1, 1974, 58 ; (d) S. J. Toal and W. C. Trogler, J. Mater. Chem., 2006, 16, 2871.

4. (a) J.-I. Aihara, J. Phys. Org. Chem., 2008, 21, 79 ; (b) N. S. Mills, J. Org. Chem., 1992, 57, 1899 .

5. D. A. Forsyth and G. A. Olah, J. Am. Chem. Soc., 1976, 98, 4086

6. (a) M. Banerjee, S. V. Lindeman and R. Rathore, J. Am. Chem. Soc., 2007, 129, 8070 ; (b) J. K. Kochi, R. Rathore and P. L. Magueres, J. Org. Chem., 2000, 65, 6826 ; (c) R. Rathore, S. H. Abdelwahed and I. A. Guzei, J. Am. Chem. Soc., 2004, 126, 13582 ; (d) P. Debroy, R. Shukla, S. V. Lindeman and R. Rathore, J. Org. Chem., 2007, 72, 1765 , and references therein.

7. M. A. Silvestri, M. Nagarajan, E. De Clercq, C. Pannecouque and M. Cushman, J. Med. Chem., 2004, 47, 3149 .

8. R. Rathore, C. L. Burns and M. I. Deselnicu, Org. Synth., 2005, 82, 1.

9. (a) F. A. Bell, A. Ledwith and D. C. Sherrington, J. Chem. Soc. C, 1969, 13, 2719 ; (b) F. A. Bell, A. Ledwith and D. C. Sherrington, J. Org. Chem., 1976, 13, 155.

10. (a) D. Sun, S. V. Lindeman, R. Rathore and J. K. Kochi, J. Chem. Soc., Perkin Trans. 2, 2001, 1585 ; (b) R. Rathore, S. V. Lindeman, A. S. Kumar and J. K. Kochi, J. Am. Chem. Soc., 1998, 120, 6931-6939.

11. Compare: P. L. Magueres, S. M. Hubig, P. Veya and J. K. Kochi, J. Am. Chem. Soc., 2000, 122, 10073 . 


\section{Footnotes}

† Electronic supplementary information (ESI) available: Synthetic details of $\mathbf{3}$ and procedure for the isolation of its cation radical. CCDC 720096-720097. For ESI and crystallographic data in CIF or other electronic format see DOI: $10.1039 / \mathrm{b} 903133 \mathrm{~b}$

‡ Crystal structure data for $3\left[\mathrm{C}_{34} \mathrm{H}_{32} \mathrm{O}_{8} \cdot \mathrm{CH}_{2} \mathrm{Cl}_{2} \cdot\left(\mathrm{CH}_{3} \mathrm{CN}\right)_{4}\right]$ (raj2z): $\mathrm{FW}=817.74$, monoclinic, $\mathrm{C2} / \mathrm{c}, a=$ 31.6750(8) $\AA$, $b=7.3983(2) \AA ̊ ., c=18.0078(4) \AA, b=106.7180(10)^{\circ}, Z=4, V=4041.60(17) \AA^{3}, D=1.344$ $\mathrm{Mg} \mathrm{m}^{-3}, T=100 \mathrm{~K}, 6231$ reflections measured, 3114 unique reflections, $R_{\text {int }}=0.0174,342$ parameters refined, $R($ all $)=0.0944, w R($ all $)=0.2397, S=1.066$ (CCDC 720097). Crystal structure data

for $3^{*}+\mathrm{SbCl}_{6} \cdot\left[\mathrm{C}_{34} \mathrm{H}_{32} \mathrm{O}_{8} \mathrm{SbCl}_{6} \cdot\left(\mathrm{CH}_{2} \mathrm{Cl}_{2}\right)_{2}\right]$ (raj3d): $\mathrm{FW}=1072.90$, triclinic, $P \overline{1}, a=13.6451(5) \AA, b=14.0770(5)$ $\AA, c=14.3621(5) \AA, \alpha=61.672(2)^{\circ}, \beta=62.275(2)^{\circ}, \gamma=70.899(2)^{\circ}, Z=2, V=2129.39(13) \AA^{3}, d=1.673$ $\mathrm{Mg} \mathrm{m}^{3}, T=100 \mathrm{~K}, 16984$ reflections measured, 6159 unique reflections, $R_{\text {int }}=0.0343,644$ parameters refined, $R($ all $)=0.0307, w R($ all $)=0.0 .0728, S=1.039($ CCDC 720096) . 